Article

\title{
Identification and Characterization of 33 Bacillus cereus sensu lato Isolates from Agricultural Fields from Eleven Widely Distributed Countries by Whole Genome Sequencing
}

\author{
Athanasios Zervas ${ }^{1}$, Marie Rønne Aggerbeck ${ }^{1}$, Henrietta Allaga ${ }^{2}$, Mustafa Güzel ${ }^{3}$, \\ Marc Hendriks ${ }^{4}$, IIona Jonuškienè ${ }^{5}$, Orsolya Kedves ${ }^{2}$, Ayse Kupeli ${ }^{6}$, Janja Lamovšek ${ }^{7}$, \\ Pascal Mülner ${ }^{8}$, Denise Munday ${ }^{9}$, Şahin Namli ${ }^{6}$, Hilal Samut ${ }^{6}$, Ružica Tomičić ${ }^{10}$, \\ Zorica Tomičić ${ }^{11}$, Filiz Yeni ${ }^{6}$, Raida Zribi Zghal ${ }^{12,13}$, Xingchen Zhao ${ }^{14}$, Vincent Sanchis-Borja ${ }^{15}$ \\ and Niels Bohse Hendriksen ${ }^{1, *}$ \\ 1 Department of Environmental Science, Aarhus University, 4000 Roskilde, Denmark; az@envs.au.dk (A.Z.); \\ mrag@envs.au.dk (M.R.A.) \\ 2 Department of Microbiology, University of Szeged, 6726 Szeged, Hungary; \\ henrietta.allaga@gmail.com (H.A.); kedvesorsolya91@gmail.com (O.K.) \\ 3 Department of Food Engineering, Hitit University, 19030 Çorum, Turkey; musguzel@gmail.com \\ 4 Wageningen Plant Research, Wageningen University, 6708PB Wageningen, The Netherlands; \\ marc.hendriks@wur.nl \\ 5 Department of Organic Chemistry, Kaunas University of Technology, 50254 Kaunas, Lithuania; \\ ilona.jonuskiene@ktu.lt \\ 6 Department of Food Engineering, Middle East Technical University, 06800 Ankara, Turkey; \\ aysekupelii@gmail.com (A.K.); snamli@metu.edu.tr (Ş.N.); hilal.samut@metu.edu.tr (H.S.); \\ filizyeni@gmail.com (F.Y.) \\ 7 Plant Protection Department, Agricultural Institute of Slovenia, 1000 Ljubljana, Slovenia; \\ Janja.Lamovsek@kis.si \\ 8 Graz University of Technology, 8010 Graz, Austria; pascal.muelner@tugraz.at \\ Sumitomo Chemical Agro Europe, 1260 Nyon, Switzerland; Denise.MUNDAY@sumitomo-chem.fr \\ 10 Faculty of Technology, University of Novi Sad, 21000 Novi Sad, Serbia; ruzica.tomicic@yahoo.com \\ 11 Institute of Food Technology, University of Novi Sad, 21000 Novi Sad, Serbia; zorica.tomicic@fins.uns.ac.rs \\ 12 Sfax Preparatory Engineering Institute, Sfax University, P.O. Box 1172, 3000 Sfax, Tunisia; raida_zz@yahoo.fr \\ 13 Centre of Biotechnology of Sfax, Biopesticides Laboratory, P.O. Box 1177, 3018 Sfax, Tunisia \\ 14 Laboratory of Food Microbiology and Food Preservation, Ghent University, 9000 Ghent, Belgium; \\ Xingchen.Zhao@UGent.be \\ 15 Micalis Institute, INRA, Université Paris-Saclay, 78350 Jouy-en-Josas, France; vincent.sanchis-borja@inra.fr \\ * Correspondence: nbh@envs.au.dk; Tel.: +45-28102452
}

Received: 10 November 2020; Accepted: 12 December 2020; Published: 18 December 2020

\begin{abstract}
The phylogeny, identification, and characterization of 33 B. cereus sensu lato isolates originating from 17 agricultural soils from 11 countries were analyzed on the basis of whole genome sequencing. Phylogenetic analyses revealed all isolates are divided into six groups, which follows the generally accepted phylogenetic division of $B$. cereus sensu lato isolates. Four different identification methods resulted in a variation in the identity of the isolates, as none of the isolates were identified as the same species by all four methods-only the recent identification method proposed directly reflected the phylogeny of the isolates. This points to the importance of describing the basis and method used for the identification. The presence and percent identity of the protein product of 19 genes potentially involved in pathogenicity divided the 33 isolates into groups corresponding to phylogenetic division of the isolates. This suggests that different pathotypes exist and that it is possible to differentiate between them by comparing the percent identity of proteins potentially involved in pathogenicity. This also reveals that a basic link between phylogeny and pathogenicity is likely to
\end{abstract}


exist. The geographical distribution of the isolates is not random: they are distributed in relation to their division into the six phylogenetic groups, which again relates to different ecotypes with different temperature growth ranges. This means that we find it easier to analyze and understand the results obtained from the 33 B. cereus sensu lato isolates in a phylogenetic, patho-type and ecotype-oriented context, than in a context based on uncertain identification at the species level.

Keywords: ecotypes; patho-types; phylogeny; geographical-distribution; Bacillus mycoides; Bacillus toyonensis; Bacillus mosaicus; Bacillus thuringiensis

\section{Introduction}

Bacillus cereus sensu lato, also known as the B. cereus group, consists of Gram-positive, rod-shaped, spore-forming bacilli, commonly isolated from soil, and other environmental and food matrices. The founders of the group are the well-known species B. cereus sensu stricto (s.s.), an opportunistic pathogen and food spoiler, B. anthracis, the etiological agent of anthrax, and B. thuringiensis, an entomopathogen, with specific strains widely used as biocontrol agents. The group also encompasses species of minor economic or medical importance, such as B. weihenstephanensis, B. mycoides and B. pseudomycoides. Since 2011, another 15 species have been described as plausible members of the group, however, the taxonomic and phylogenetic relationships of these bacteria are still unclarified. During the last 20 years, genotypic methods have revealed that the traditional practical classification and identification methods are not necessarily consistent with the group's phylogenetic classification. Notably, fluorescent amplified fragment-length polymorphism patterns (AFLP) and multiple locus sequence typing (MLST) have revealed the existence of three broad phylogenetic clades further divided into seven major groups, mentioned as phylogenetic groups I to VII [1-3]. These, often, do not correspond to their phenotypic identification, e.g., strains affiliated to B. thuringiensis are found in at least four of the phylogenetic groups since their specific insecticidal feature is plasmid-borne and can be horizontally transferred [1]. Lately, whole genome sequencing has been used for analyzing the phylogeny of the group. Liu et al. [4] analyzed 224 B. cereus group strains by the Genome BLAST (Basic Local Assignment Search Tool) Distance Phylogeny approach based on digital DNA:DNA hybridization. Their analysis separated the strains into 30 clusters, representing eleven known, partially merged species, and accordingly, 19-20 putative novel species. This approach has recently been used to describe a general automated high-throughput platform for state-of-the-art genome-based taxonomy [5]. Bazinet [6], who analyzed 498 B. cereus group genomes with different phylogenetic analysis tools, found that, irrespective of data source and analysis methodology, the three-clade and seven-group classification system was recapitulated, suggesting that the broad phylogenetic structure suggested by AFLP and MLST has been inferred correctly. Recently, Carroll et al. [7] used an average nucleotide identity (ANI) approach to make a proposal for a new taxonomic nomenclature of the B. cereus group by analyzing 2231 genomes, proposing 18 genomo-species to exist, of which six are undescribed. However, the analysis maintained the known overall phylogenetic structure with three clades and seven groups. In addition, they identified outlying groups-groups that still need to be characterized in detail.

Guinebretiere et al. [2] recognized an adaptation to different growth temperatures within the $B$. cereus group, concurrent with the above-mentioned seven phylogenetic groups, for example, group VI members are psychro-coldtolerant with a growth range of between 5 and $37{ }^{\circ} \mathrm{C}$, while members of group VII are thermotolerant with a growth range between 20 and $50{ }^{\circ} \mathrm{C}$. This adaptation has been corroborated by a strong observed relationship between divergence in ribosomal proteins, the seven phylogenetic groups and an adaptation of the $B$. cereus group to different temperature growth ranges [8]. These findings, along with other studies, suggested that the $B$. cereus group should be considered a single evolutionary unit characterized by clonal expansion and adaptation to various environmental factors that led to the formation of distinct phenotypes, also mentioned as ecotypes, 
within major phylogenetic lineages [9-11]. These suggestions relate to the fact that cytotoxic activity levels and toxin distribution vary accordingly to the phylogenetic group, implying that the group differs in food poisoning potential [12].

The pathogenicity of $B$. cereus group bacteria is, apart from anthrax and some anthrax-like diseases, caused by $B$. anthracis and a few $B$. cereus strains, notably two gastro-intestinal diseases, although several somatic diseases have also been described [13]. The two gastro-intestinal diseases are the emetic syndrome and diarrheal syndrome. The emetic syndrome is caused by the toxin cereulide, which is pre-formed in food and it is primarily observed in a distinct subgroup within the phylogenetic group III of B. cereus [14]. The diarrheal syndrome has notably been linked to three pore-forming enterotoxins thought to be produced in the intestine. They are two three-component toxins: the nonhemolytic enterotoxin (Nhe), the hemolytic toxin $(\mathrm{Hbl})$ and the single protein cytotoxin (CytK). However, phospholipases, sphingomyelinases, hemolysins, proteinases and peptidases likely represent additional virulence factors involved in the syndrome [14]. These enterotoxins and additional virulence factors are broadly distributed among the members of the B. cereus group. Carroll et al. [15] developed a tool for identifying the enterotoxins and some additional virulence factors for whole genome sequenced B. cereus group members.

The aims of this paper are to identify and characterize 34 whole genome sequenced strains isolated from agricultural soils from eleven countries in a phylogenetic context. The analyses are based on different tools available for identification based on whole genome sequences (WGS) and are compared to an ecotype approach for characterization, including temperature growth range and presence of virulence factors.

\section{Materials and Methods}

Surface soil samples were collected from 17 fields in 11 countries spanning approximately 2100 $\mathrm{km}$ from north to south (Denmark to Tunisia) and $1500 \mathrm{~km}$ west to east (Belgium to Turkey) during January 2019. Details about the localities are given in Table 1.

The soil samples were gently mixed in sterile plastic bags. Approximately $2.5 \mathrm{~g}$ of the mixed soil was added to $25 \mathrm{~mL}$ demineralized water and further mixed for $5 \mathrm{~min}$ by a multi-wrist shaker (Lab-line, speed 5). Afterwards, $10 \mathrm{~mL}$ of the suspensions were heat-treated in a water bath $\left(65^{\circ} \mathrm{C}\right.$ for $\left.35 \mathrm{~min}\right)$. Ten-fold serial dilutions of the suspensions were plated on T3 sporulation agar [16] and incubated for one day at $30^{\circ} \mathrm{C}$. Two colonies having a rugose, ice-crystal-like appearance and a diameter $>1 \mathrm{~mm}$ were randomly selected as being $B$. cereus sensu lato and sub-cultured on T3-agar.

For DNA preparation, bacterial cultures were plated on Luria-Bertani (LB) agar and incubated overnight at $30^{\circ} \mathrm{C}$. Bacterial biomass, corresponding to a 1-2 mm diameter colony, was transferred to $200 \mu \mathrm{L}$ Tris-EDTA buffer. Bacteria were lysed by incubation at $102{ }^{\circ} \mathrm{C}$ for $10 \mathrm{~min}$, and debris was removed by centrifugation at $15,000 \times g$ for $3 \mathrm{~min}$. The DNA-containing supernatant was transferred to a new microcentrifuge tube and stored at $4{ }^{\circ} \mathrm{C}$. Multiplex PCR for the affiliation of the bacteria to the $B$. cereus-group were run as described in Hansen et al. [17]. PCR of the 16S-23S rRNA gene (rDNA) spacer region with the L1-G1 [18] primer set was used as a control of DNA quality and for the procedure. PCR products were visualized by $1.5 \%$ agarose gel electrophoresis, using MW VI (Roche) as the molecular weight marker, on an Azure c200 gel imaging system (Azure Biosystems, Dublin, CA, USA). 
Table 1. Origin and characteristics of agricultural fields used for isolation of B. cereus sensu lato bacteria.

\begin{tabular}{|c|c|c|c|c|c|}
\hline Isolate Number & Country & GPS-Coordinates & Meters above Sea Level & Crop & $\begin{array}{c}\text { Yearly Mean } \\
\text { Temperature }\left({ }^{\circ} \mathrm{C}\right)\end{array}$ \\
\hline $\mathrm{N} 1$ and N2 & Lithuania & $\begin{array}{l}54.864 \\
23.941\end{array}$ & 50 & Vegetables & 6.4 \\
\hline $\mathrm{N} 3$ and N4 & Tunisia & $\begin{array}{l}34.5117 \\
10.4924\end{array}$ & 200 & Olive trees & 18.1 \\
\hline N5 and N6 & Netherlands & $\begin{array}{c}51.966 \\
5.655\end{array}$ & 9 & Leak & 9.2 \\
\hline N7 and N8 & Slovenia & $\begin{array}{l}46.1434 \\
14.5580\end{array}$ & 265 & Oat & 10.4 \\
\hline N9 and N10 & Switzerland & $\begin{array}{l}46.3919 \\
6.21164\end{array}$ & 450 & Livestock & 9.2 \\
\hline N11 and N12 & Hungary & $\begin{array}{l}47.3827 \\
17.4992\end{array}$ & 135 & Maize & 11.1 \\
\hline $\mathrm{N} 13$ and N14 & Hungary & $\begin{array}{l}46.0559 \\
19.2622\end{array}$ & 95 & Pea & 11.1 \\
\hline N15 and N16 & Serbia & $\begin{array}{l}45.1908 \\
19.2101\end{array}$ & 88 & Fallow & 11.3 \\
\hline N17 and N18 & Serbia & $\begin{array}{l}45.1908 \\
19.2101\end{array}$ & 88 & Fallow & 11.3 \\
\hline $\mathrm{N} 19$ and N20 & Turkey & $\begin{array}{l}39.9672 \\
32.6623\end{array}$ & 938 & Lemon & 10.9 \\
\hline $\mathrm{N} 21$ and N22 & Turkey & $\begin{array}{l}40.0808 \\
34.1200\end{array}$ & 780 & Wheat, Barley & 10.9 \\
\hline $\mathrm{N} 23$ and N24 & Turkey & $\begin{array}{l}39.9040 \\
32.6345\end{array}$ & 900 & Garden & 10.9 \\
\hline $\mathrm{N} 25$ and N26 & Turkey & $\begin{array}{l}39.5456 \\
33.4436\end{array}$ & 1000 & Grass & 10.9 \\
\hline N27 and N28 & Turkey & $\begin{array}{l}40.0047 \\
32.5142\end{array}$ & 1066 & Grass & 10.9 \\
\hline N29 and N30 & Denmark & $\begin{array}{l}55.697 \\
12.103\end{array}$ & 5 & Grass & 7.8 \\
\hline N31 and N32 & Germany & $\begin{array}{l}52.359 \\
13.308\end{array}$ & 42 & Potato & 10.2 \\
\hline N33 and N34 & Belgium & $\begin{array}{c}51.138 \\
3.938\end{array}$ & 6 & Tree Nursery & 10.2 \\
\hline
\end{tabular}

Thirty-four isolates for whole genome sequencing were grown on Luria Bertani broth (LB) at room temperature for $24 \mathrm{~h}$. DNA was extracted using the Ultraclean Microbial DNA isolation kit (Qiagen, Hilden, Germany) and quantified on a Qubit 2.0 (Life Technologies, Carlsbad, CA, USA). Sequencing libraries were prepared using the Nextera XT sample preparation kit (Illumina, Cambridge, United Kingdom) following the manufacturer's instructions. The libraries were sequenced on the Illumina Nextseq 500 platform using the $150 \mathrm{bp}$ pair-end reads technology. The obtained raw reads were trimmed for quality, their adapters removed using fastp [19], and de novo assemblies were performed using SPAdes (version 3.14.1, St. Peterburg, Russia). Annotations of the assembled draft genomes were done using Prokka (version 1.14.5, Carlton, Australia) under default settings and databases [20].

MLST analysis on the selected strains was performed using the Center for genomic epidemiology platform for MLST [21]. This service uses a B. cereus MLST scheme developed by Priest et al. [1] for the analysis. The affiliation of the strains to the phylogenetic group by MLST was done using the group of its nearest neighbor, for which the affiliation is known in the MLST database.

Traditional identification was based on colony morphology, delineation to the B. cereus group by PCR, reaction on mannitol Egg Yolk Polymyxin agar plates, phase contrast microscopy and differentiation of $B$. cereus and $B$. weihenstephanensis by the presence of the gene for the cold-shock protein $\operatorname{csp} A$ variant specific for this species identified in the whole genome sequence [22].

Full-length 16S rRNA sequences from each sample were extracted from the resulting annotations from Prokka and aligned using MAFFT v 7.450 [23] with default settings, implemented in Geneious Prime 2020.2 (Biomatters, Auckland, New Zeland). A phylogenetic tree was constructed on RAxML (version 4.0 implemented in Geneious Prime) [24] using the GTR GAMMA model under the "Rapid Bootstrapping and search for best-scoring ML tree" algorithm with 100 bootstraps replicates, embedded in Geneious Prime 2020.2 [24]. 
In silico taxonomic classification of the isolates based on ANI using their draft-assembled genomes was performed using Btyper3 under default settings and adding the virulence flag to check for biovars Anthracis or Emeticus [7].

In silico taxonomic classification of the isolates based on digital DNA:DNA hybridization using their draft assembled genomes was performed using TYGS [5].

Virulence-based classification of the isolates in this analysis was performed using Btyper [15]. This tool was used for classifying isolates to phylogenetic groups based on the sequence of panC using the default setting corresponding to "draft genomes", as described in the program's manual (https://github.com/lmc297/BTyper).

Complete and draft genome assemblies analyzed in this investigation are deposited in GenBank under BioProject PRJNA681344.

\section{Results}

In this study, we isolated 34 B. cereus group bacteria from 17 agricultural fields originating from 11 countries (Table 1) based on colony morphology. The identity of the isolates as Bacillus cereus sensu lato was confirmed by a multiplex PCR assay. All the 34 isolates were whole genome sequenced. The overall genomic features of the isolates are presented in Table 2 . The estimated number of bases and coding sequences (CDS) for isolate N32 is approximately two times the size of that estimated for the other 33 isolates (Table 2). Further analysis with the isolate N32 revealed that it was composed of two species related to B. cereus sensu lato and Lysinibacillus spp. For that reason, N32 is omitted from further analysis.

The estimated number of bases and CDS vary between 5.5 and 7.1 MB and 5550 and 6433, respectively. Averages for the number of bases are $6.0 \mathrm{MB}$ and 5965 for the CDS. In comparison, the number of contigs varies between 173 and 4682, with an average of 709. The number of tRNA and rRNA genes varies between 91 and 139 and 6 and 20, respectively.

Results of WGS-based MLST of the 33 isolates are presented on Table 3. The isolates comprise 29 sequence types (ST), of which 11 are new, while 11 of these sequence types are determined with some uncertainty, as no allele in the current database matches with $100 \%$ identity and coverage to the seven analyzed genes. Three of the isolates belong to sequence type 12, two belong to sequence types 56 and 434 , and the remaining 26 isolates belong to different sequence types. Table 3 also highlights the six different phylogenetic groups (based on panC sequences) to which the isolates belong. According to Guinebretièere et al. [2], these groups are referred to as group I, II, III, IV, V and VI, to which 1, 3, 1, 10, 8 and 10 isolates belong, respectively. The division of the isolates into these groups was confirmed by the MLST analysis; however, in the case of some isolates, there is a level of uncertainty as the MLST profile is new. 
Table 2. Overall whole genome characteristics of 33 B. cereus sensu lato isolates. Bases = number of nucleotides, Contigs = number of contigs, $\mathrm{CDS}=$ number of coding sequences, $\mathrm{tRNA}=$ number of tRNA genes, rRNA = number of rRNA genes; GC-content = percentage guanine-cytosine content

\begin{tabular}{|c|c|c|c|c|c|c|}
\hline Isolate & Bases & Contigs & CDS & tRNA & rRNA & GC content \\
\hline N1 & 6589056 & 1486 & 6332 & 139 & 12 & 34.87 \\
\hline N2 & 6208593 & 362 & 6112 & 116 & 10 & 34.7 \\
\hline N3 & 5981260 & 1394 & 5801 & 98 & 10 & 35.18 \\
\hline N4 & 5628374 & 283 & 5577 & 115 & 11 & 35.01 \\
\hline N5 & 6039339 & 435 & 6023 & 120 & 9 & 35.08 \\
\hline N6 & 6050091 & 858 & 6102 & 139 & 12 & 35.33 \\
\hline N7 & 7090662 & 4682 & 6057 & 129 & 14 & 37.86 \\
\hline N8 & 5963382 & 392 & 6054 & 102 & 12 & 35.2 \\
\hline N9 & 5731016 & 563 & 5730 & 112 & 12 & 35.31 \\
\hline N10 & 5648760 & 410 & 5647 & 128 & 11 & 35.25 \\
\hline N11 & 6015328 & 286 & 5869 & 109 & 12 & 35.06 \\
\hline N12 & 6179004 & 1900 & 5902 & 125 & 16 & 35.4 \\
\hline N13 & 5920438 & 304 & 5853 & 112 & 13 & 34.9 \\
\hline N14 & 5687870 & 332 & 5733 & 132 & 8 & 35.17 \\
\hline N15 & 6040251 & 455 & 5965 & 126 & 12 & 34.99 \\
\hline N16 & 5783502 & 405 & 5769 & 120 & 11 & 35.09 \\
\hline N17 & 6225349 & 391 & 6198 & 98 & 7 & 34.91 \\
\hline N18 & 5976955 & 349 & 5862 & 94 & 10 & 35.05 \\
\hline N19 & 6310391 & 1305 & 6317 & 105 & 9 & 35.3 \\
\hline N20 & 6366475 & 989 & 6433 & 104 & 8 & 35.18 \\
\hline N21 & 6047278 & 805 & 6041 & 112 & 20 & 35.48 \\
\hline N22 & 5686548 & 425 & 5689 & 122 & 11 & 35.1 \\
\hline N23 & 6246356 & 279 & 6250 & 105 & 7 & 34.76 \\
\hline N24 & 6083667 & 332 & 6065 & 100 & 7 & 34.92 \\
\hline N25 & 6552745 & 545 & 6375 & 96 & 6 & 34.68 \\
\hline N26 & 6346459 & 979 & 6410 & 101 & 7 & 35.18 \\
\hline N27 & 6484007 & 279 & 6360 & 91 & 6 & 34.67 \\
\hline N28 & 5996583 & 320 & 6003 & 102 & 10 & 35,13 \\
\hline N29 & 5603679 & 484 & 5593 & 95 & 11 & 35.18 \\
\hline N30 & 5706629 & 631 & 5665 & 99 & 9 & 35.3 \\
\hline N31 & 5996429 & 274 & 5885 & 94 & 11 & 34.98 \\
\hline N33 & 5528708 & 290 & 5550 & 109 & 14 & 35.32 \\
\hline N34 & 5640513 & 173 & 5616 & 92 & 9 & 35.28 \\
\hline
\end{tabular}


Table 3. PanC and multiple loci sequence typing (MLST) characterization of 33 B. cereus sensu lato isolates. * Determined with uncertainty: ? = New profile. glp (glycerol uptake facilitator protein), gmk (guanylate kinase, putative), ilvD (dihydroxy-acid dehydratase), pta (phosphate acetyltransferase), pur (phosphoribosylaminoimidazolecarboxamide), pycA (pyruvate carboxylase), tpi (triosephosphate isomerase).

\begin{tabular}{|c|c|c|c|c|c|c|c|c|c|c|}
\hline NR & Country & $\begin{array}{l}\text { Phylogenetic } \\
\text { Group (panC) }\end{array}$ & $\begin{array}{l}\text { MLST } \\
\text { Profile }\end{array}$ & $g l p$ & $g m k$ & $i l v$ & $p t a$ & pur & pyc & $t p i$ \\
\hline N1 & Lithuania & clade 4 & $?$ & 14 & $8 *$ & 48 & 45 & 58 & 51 & 7 \\
\hline $\mathrm{N} 2$ & Lithuania & clade 4 & $?$ & 285 & 8 & $283 *$ & $45^{*}$ & 58 & 87 & 7 \\
\hline N3 & Tunesia & clade 5 & 223 & 43 & 26 & 35 & 42 & 39 & 41 & 63 \\
\hline N4 & Tunesia & clade 4 & 1009 & 16 & 6 & 170 & 9 & 4 & 7 & 21 \\
\hline N5 & Nederlands & clade 2 & 616 & 81 & 53 & 117 & 71 & 113 & 93 & 80 \\
\hline N6 & Nederlands & clade 2 & $?^{*}$ & 110 & 56 & $111^{*}$ & 188 & 64 & 96 & 26 \\
\hline N7 & Slovenia & clade 6 & 434 & 26 & 21 & 126 & 104 & 78 & 32 & 18 \\
\hline N8 & Slovenia & clade 6 & $?^{*}$ & 274 & 115 & 227 & 200 & 195 & 170 & $163 *$ \\
\hline N9 & Switzerland & clade 6 & 428 & 108 & 51 & 130 & 121 & 109 & 92 & 79 \\
\hline N10 & Switzerland & clade 6 & 434 & 26 & 21 & 126 & 104 & 78 & 32 & 18 \\
\hline N11 & Hungary & clade 5 & $?^{*}$ & 87 & $26^{*}$ & 78 & 90 & 273 & 41 & 30 \\
\hline N12 & Hungary & clade 5 & $?$ & 87 & 26 & 78 & 90 & 273 & 220 & 30 \\
\hline N13 & Hungary & clade 4 & 23 & 15 & 7 & 7 & 2 & 5 & 8 & 13 \\
\hline N14 & Hungary & clade 2 & ?* & $118^{*}$ & 35 & $171^{*}$ & 22 & 96 & 20 & 26 \\
\hline N15 & Serbia & clade 5 & $72 *$ & 43 & $26 *$ & 35 & 40 & 39 & 41 & 30 \\
\hline N16 & Serbia & clade 3 & $1766^{*}$ & $229^{*}$ & 5 & 271 & 240 & 281 & 183 & 190 \\
\hline N17 & Serbia & clade 5 & 278 & 83 & 26 & 35 & 42 & 39 & 71 & 30 \\
\hline N18 & Serbia & clade 5 & 1484 * & 43 & 26 & 78 & 42 & $39 *$ & 71 & $30 *$ \\
\hline N19 & Turkey & clade 6 & ?* & $75 *$ & $104^{*}$ & $303^{*}$ & $15^{*}$ & $103 *$ & $202 *$ & $128 *$ \\
\hline N20 & Turkey & clade 4 & 56 & 15 & 7 & 7 & 2 & 7 & 26 & 13 \\
\hline N21 & Turkey & clade 1 & $?^{*}$ & 134 & 13 & 274 & 253 & 84 & 44 & $35^{*}$ \\
\hline N22 & Turkey & clade 4 & 4 & 13 & 8 & 8 & 11 & 11 & 12 & 7 \\
\hline $\mathrm{N} 23$ & Turkey & clade 4 & 12 & 15 & 7 & 7 & 2 & 7 & 10 & 13 \\
\hline N24 & Turkey & clade 5 & 886 & 43 & 50 & 35 & 125 & 70 & 41 & 30 \\
\hline N25 & Turkey & clade 4 & 12 & 15 & 7 & 7 & 2 & 7 & 10 & 13 \\
\hline N26 & Turkey & clade 4 & 56 & 15 & 7 & 7 & 2 & 7 & 26 & 13 \\
\hline N27 & Turkey & clade 4 & 12 & 15 & 7 & 7 & 2 & 7 & 10 & 13 \\
\hline N28 & Turkey & clade 6 & $?$ & 8 & 10 & 22 & 15 & 35 & 9 & 11 \\
\hline N29 & Denmark & clade 6 & $635^{*}$ & 26 & 21 & $104 *$ & 68 & $27^{*}$ & 32 & 18 \\
\hline N30 & Denmark & clade 6 & $?^{*}$ & 108 & 139 & 104 & $15^{*}$ & 221 & 92 & 79 \\
\hline N31 & Austria & clade 5 & 487 & 83 & 26 & 143 & 133 & 91 & 41 & 30 \\
\hline N33 & Belgium & clade 6 & 254 & 103 & 63 & 5 & 15 & 94 & 70 & 11 \\
\hline N34 & Belgium & clade 6 & 734 & 25 & 10 & 22 & 165 & 83 & 23 & 11 \\
\hline
\end{tabular}

Figure 1 shows a phylogenetic tree for the 33 isolates based on Average Nucleotide Identity (ANI). The phylogenetic tree indicates that this methodology divides the isolates into six major groups (I-VI). This division of the isolates between these groups corresponds exactly to the division based on panC sequencing and MLST.

The identification of the isolates to the species level was performed by four different methods (Table 4). Twenty-three of the isolates were identified as B. cereus and the rest as B. weihenstephanensis by traditional identification. According to 16 rRNA gene sequence analysis, twelve isolates were identified as $B$. cereus, eight as $B$. mycoides, seven as $B$. wiedmanii, two as $B$. thuringiensi and one as B. pseudomycoides or B. toyonenisis, while two were identified as Bacillus sp. and one isolate was not identified. The ANI-based tool in Btyper3 identified six isolates as B. cereus SS, four as B. cereus Biovar thuringiensis, ten as B. mycoides, eight as B. toyonensis, four as B. mosaicus and one as B. pseudomycoides. The isolates identified as B. cereus biovar thuringiensis possessed either Cry75Aa3 (N1), Vip1Ad1 and 
Vip2Ba2 (N2), or Vip1Ad1 and Vip2Ad1 (N25 and N27). The TYGS tool based on DNA:DNA in silico hybridization identified ten isolates as $B$. toyonensis, three as B. mycoides, two as B. cereus, two as $B$. proteolyticus, one as $B$. pseudomycoides and one as $B$. wiedmanii, while 14 isolates were identified as belonging to seven new species.

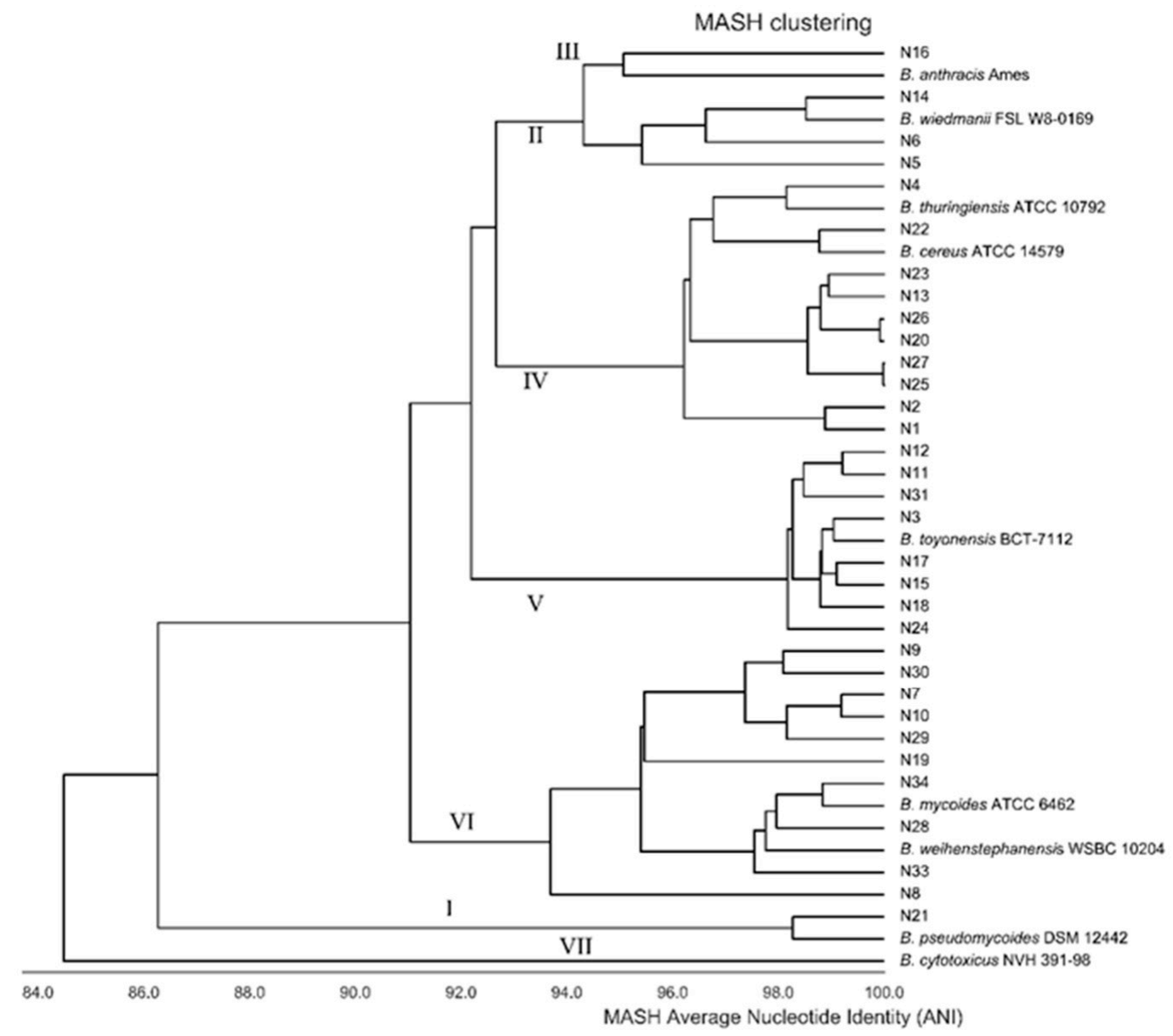

Figure 1. Average Nucleotide Identity (ANI)-based phylogenetic tree of 33 B. cereus s.l. constructed by MASH clustering. Nine strains referring to different species within the group are included. Further, the affiliation of the different clusters' relations to the proposed phylogenetic groups I-VII [2] is shown.

The relation between the panC and MLST classification of the isolates into six phylogenetic groups is shown in Table 4. The relation to the traditional identification is clear as the B. cereus belongs to group I, II, III, IV and V, while B. weihenstephanensis belongs to group VI. For the identification based on $16 \mathrm{~S}$ rRNA genes, it is not clear, as, e.g., the isolates belonging to B. wiedmanii belong to groups II, IV and $\mathrm{V}$, together with isolates identified as four other species, while B. mycoides constitute group VI, together with one B. wiedmanii. For the identification by the ANI-based method, the relation is clear, as the four identified species belong separately to groups I, IV, V or VI, while group II and III isolates belong to the newly proposed species $B$. mosaicus. For the DNA:DNA hybridization-based method, the relationship is unclear, except for the strains identified as $B$. toyonensis, which all except one belong to group 5. It is also worth taking into account that none of the 33 isolates belong to the same species, when identified by the four methods.

Table 5 shows the percentage identity of nineteen translated virulence genes to the genes found in the BTyper virulence database [15]. We restricted the analysis to genes for the virulence factors and omitted regulatory elements. Further, we omitted bceT, as the existence of this gene is debated [25]. 
Table 4. Identification of 33 B. cereus sensu lato by four different methods.

\begin{tabular}{|c|c|c|c|c|c|c|}
\hline Isolate & Country & Phylogeny & Traditional & $\begin{array}{l}\text { 16S RNA } \\
\text { gene }\end{array}$ & Species ANI & $\begin{array}{c}\text { Species } \\
\text { DNA/DNA }\end{array}$ \\
\hline N21 & Turkey & clade 1 & B. cereus & B. cereus & B. pseudomycoides & B pseudomycoides \\
\hline N14 & Hungary & clade 2 & B. cereus & B. cereus & B. mosaicus & B toyonensis \\
\hline N16 & Serbia & clade 2 & B. cereus & B. cereus & B. mosaicus & New species 2 \\
\hline N5 & Nederlands & clade 2 & B. cereus & B. cereus & B. mosaicus & New species 3 \\
\hline N6 & Nederlands & clade 2 & B. cereus & B. cereus & B. mosaicus & New species 5 \\
\hline N1 & Lithuania & clade 4 & B. cereus & B. cereus & $\begin{array}{l}\text { B. cereus s.s. } \\
\text { biovar } \\
\text { Thuringiensis; } \\
\text { B. thuringiensis }\end{array}$ & New species 1 \\
\hline N13 & Hungary & clade 4 & B. cereus & B. cereus & B. cereus s.s. & B. wiedmanii \\
\hline N2 & Lithuania & clade 4 & B. cereus & B. cereus & $\begin{array}{c}\text { B. cereus s.s. } \\
\text { biovar } \\
\text { Thuringiensis; } \\
\text { B. thuringiensis }\end{array}$ & New species 1 \\
\hline N20 & Turkey & clade 4 & B. cereus & B. cereus & B. cereus s.s. & New species 7 \\
\hline N22 & Turkey & clade 4 & B. cereus & B. cereus & B. cereus s.s. & B cereus \\
\hline N23 & Turkey & clade 4 & B. cereus & B. mycoides & B. cereus s.s. & New species 7 \\
\hline N25 & Turkey & clade 4 & B. cereus & B. mycoides & $\begin{array}{c}\text { B. cereus s.s. } \\
\text { biovar } \\
\text { Thuringiensis; } \\
\text { B. thuringiensis }\end{array}$ & New species 7 \\
\hline N26 & Turkey & clade 4 & B. cereus & B. mycoides & B. cereus s.s. & New species 7 \\
\hline $\mathrm{N} 27$ & Turkey & clade 4 & B. cereus & B. mycoides & $\begin{array}{c}\text { B. cereus s.s. } \\
\text { biovar } \\
\text { Thuringiensis; } \\
\text { B. thuringiensis }\end{array}$ & New species 7 \\
\hline N4 & Tunesia & clade 4 & B. cereus & B. mycoides & B. cereus s.s. & Bacillus cereus \\
\hline N11 & Hungary & clade 5 & B. cereus & B. mycoides & B. toyonensis & B toyonensis \\
\hline N12 & Hungary & clade 5 & B. cereus & B. mycoides & B. toyonensis & B. toyonensis \\
\hline N15 & Serbia & clade 5 & B. cereus & B. mycoides & B. toyonensis & B.toyonensis \\
\hline N17 & Serbia & clade 5 & B. cereus & $\begin{array}{c}\text { B. } \\
\text { pseudomycoides }\end{array}$ & B. toyonensis & B toyonensis \\
\hline N18 & Serbia & clade 5 & B. cereus & B. $s p$ & B. toyonensis & B toyonensis \\
\hline N24 & Turkey & clade 5 & B. cereus & B. $s p$. & B. toyonensis & B toyonensis \\
\hline N3 & Tunesia & clade 5 & B. cereus & $\begin{array}{c}B . \\
\text { thuringiensis }\end{array}$ & B. toyonensis & B. toyonensis \\
\hline N31 & Austria & clade 5 & B. cereus & $\begin{array}{c}B . \\
\text { thuringiensis }\end{array}$ & B. toyonensis & B toyonensis \\
\hline N10 & Switzerland & clade 6 & $\begin{array}{c}\text { B. } \\
\text { weihenstephanensis }\end{array}$ & B. toyonensis & B. mycoides & B toyonensis \\
\hline N19 & Turkey & clade 6 & $\begin{array}{c}\text { B. } \\
\text { weihenstephanensis }\end{array}$ & B. wiedmanii & B. mycoides & New species 6 \\
\hline N28 & Turkey & clade 6 & $\begin{array}{c}\text { B. } \\
\text { weihenstephanensis }\end{array}$ & B. wiedmanii & B. mycoides & B. mycoides \\
\hline N29 & Denmark & clade 6 & $\begin{array}{c}B . \\
\text { weihenstephanensis }\end{array}$ & B. wiedmanii & B. mycoides & New species 4 \\
\hline N30 & Denmark & clade 6 & $\begin{array}{c}\text { B. } \\
\text { weihenstephanensis }\end{array}$ & B. wiedmanii & B. mycoides & New species 4 \\
\hline N33 & Belgium & clade 6 & $\begin{array}{c}\text { B. } \\
\text { weihenstephanensis }\end{array}$ & B. wiedmanii & B. mycoides & $B$ mycoides \\
\hline N34 & Belgium & clade 6 & $\begin{array}{c}B . \\
\text { weihenstephanensis }\end{array}$ & B. wiedmanii & B. mycoides & B mycoides \\
\hline N7 & Slovenia & clade 6 & $\begin{array}{c}\text { B. } \\
\text { weihenstephanensis }\end{array}$ & B. wiedmanii & B. mycoides & B. proteolyticus \\
\hline N8 & Slovenia & clade 6 & $\begin{array}{c}\text { B. } \\
\text { weihenstephanensis }\end{array}$ & $\begin{array}{c}\text { Not } \\
\text { identified }\end{array}$ & B. mycoides & $\begin{array}{c}\text { Bacillus } \\
\text { proteolyticus }\end{array}$ \\
\hline N9 & Switzerland & clade 6 & $\begin{array}{c}\text { B. } \\
\text { weihenstephanensis }\end{array}$ & B. mycoides & B. mycoides & New species 4 \\
\hline
\end{tabular}


Table 5. Presence and percentage identity to the translated genes found in the BTyper virulence database of 19 genes potentially involved in pathogenesis at the protein level in 33 B. cereus sensu lato isolates.

\begin{tabular}{|c|c|c|c|c|c|c|c|c|c|c|c|c|c|c|c|c|c|c|c|c|}
\hline Isolate & Group & cerA & cerB & clo & cytK2 & entA & entFM & hblA & hblB & hblc & hblcD & hlyII & inhA1 & inhA2 & nheA & nheB & nheC & plcA & plcB & sph \\
\hline N21 & I & 89 & 0 & 0 & 0 & 91 & 71 & 89 & 0 & 85 & 88 & 0 & 83 & 86 & 74 & 86 & 79 & 0 & 89 & 0 \\
\hline N14 & II & 95 & 90 & 98 & 0 & 96 & 94 & 95 & 87 & 94 & 99 & 0 & 94 & 96 & 96 & 100 & 95 & 94 & 95 & 98 \\
\hline N16 & II & 95 & 88 & 96 & 0 & 94 & 92 & 99 & 96 & 99 & 100 & 96 & 94 & 96 & 97 & 100 & 94 & 96 & 95 & 96 \\
\hline N5 & II & 96 & 89 & 99 & 0 & 94 & 95 & 95 & 86 & 94 & 100 & 96 & 93 & 97 & 97 & 100 & 95 & 94 & 96 & 97 \\
\hline N6 & II & 95 & 90 & 95 & 0 & 97 & 95 & 98 & 87 & 95 & 99 & 95 & 94 & 96 & 97 & 99 & 95 & 94 & 95 & 98 \\
\hline N1 & IV & 100 & 94 & 99 & 98 & 98 & 97 & 99 & 98 & 98 & 100 & 0 & 98 & 99 & 99 & 100 & 99 & 95 & 100 & 91 \\
\hline N13 & IV & 100 & 95 & 99 & 0 & 95 & 95 & 99 & 98 & 98 & 100 & 99 & 94 & 99 & 100 & 100 & 98 & 96 & 100 & 91 \\
\hline N2 & IV & 100 & 94 & 99 & 99 & 97 & 92 & 99 & 98 & 98 & 100 & 0 & 98 & 99 & 99 & 100 & 98 & 95 & 100 & 90 \\
\hline N20 & IV & 100 & 98 & 99 & 0 & 95 & 95 & 99 & 98 & 98 & 100 & 99 & 94 & 99 & 100 & 100 & 98 & 96 & 100 & 90 \\
\hline N22 & IV & 100 & 95 & 99 & 100 & 99 & 97 & 99 & 99 & 100 & 100 & 100 & 100 & 100 & 100 & 100 & 99 & 100 & 100 & 92 \\
\hline N23 & IV & 100 & 95 & 99 & 0 & 95 & 93 & 99 & 98 & 98 & 100 & 99 & 94 & 99 & 100 & 100 & 98 & 96 & 100 & 91 \\
\hline N25 & IV & 100 & 95 & 99 & 97 & 95 & 94 & 99 & 98 & 98 & 100 & 99 & 94 & 98 & 100 & 100 & 98 & 96 & 100 & 91 \\
\hline N26 & IV & 100 & 0 & 99 & 0 & 95 & 95 & 99 & 98 & 98 & 100 & 99 & 94 & 99 & 100 & 100 & 98 & 96 & 100 & 90 \\
\hline N27 & IV & 100 & 95 & 99 & 97 & 95 & 94 & 99 & 98 & 98 & 100 & 99 & 94 & 98 & 100 & 100 & 98 & 96 & 100 & 91 \\
\hline N4 & IV & 100 & 95 & 99 & 99 & 98 & 95 & 99 & 98 & 99 & 100 & 99 & 94 & 99 & 99 & 100 & 98 & 97 & 100 & 92 \\
\hline N11 & V & 98 & 90 & 91 & 0 & 97 & 90 & 93 & 86 & 94 & 99 & 0 & 96 & 97 & 97 & 100 & 93 & 90 & 98 & 94 \\
\hline N12 & $\mathrm{V}$ & 99 & 89 & 92 & 0 & 95 & 90 & 92 & 86 & 94 & 99 & 0 & 96 & 97 & 97 & 100 & 94 & 90 & 99 & 93 \\
\hline N15 & $\mathrm{V}$ & 98 & 89 & 93 & 0 & 96 & 90 & 95 & 85 & 95 & 99 & 0 & 94 & 97 & 96 & 100 & 94 & 90 & 98 & 93 \\
\hline N17 & $\mathrm{V}$ & 99 & 89 & 0 & 0 & 97 & 90 & 95 & 86 & 95 & 100 & 0 & 94 & 97 & 96 & 100 & 94 & 90 & 99 & 93 \\
\hline N18 & $\mathrm{V}$ & 99 & 89 & 0 & 0 & 97 & 90 & 95 & 86 & 95 & 100 & 0 & 94 & 97 & 96 & 100 & 94 & 90 & 99 & 93 \\
\hline N24 & V & 99 & 89 & 93 & 0 & 97 & 90 & 95 & 86 & 95 & 99 & 0 & 94 & 97 & 96 & 100 & 94 & 91 & 99 & 93 \\
\hline N3 & V & 98 & 89 & 93 & 0 & 96 & 90 & 95 & 86 & 95 & 99 & 0 & 94 & 97 & 96 & 100 & 94 & 90 & 98 & 93 \\
\hline
\end{tabular}


Table 5. Cont.

\begin{tabular}{|c|c|c|c|c|c|c|c|c|c|c|c|c|c|c|c|c|c|c|c|c|}
\hline Isolate & Group & cerA & cerB & clo & cytK2 & ent $A$ & entFM & hblA & hblB & hblC & hblcD & hlyII & inhA1 & inhA2 & nheA & nheB & nheC & plcA & plcB & sph \\
\hline N31 & $\mathrm{V}$ & 99 & 89 & 93 & 98 & 97 & 90 & 95 & 86 & 94 & 99 & 0 & 95 & 97 & 97 & 100 & 93 & 91 & 99 & 93 \\
\hline N10 & VI & 98 & 89 & 97 & 0 & 88 & 88 & 92 & 87 & 84 & 94 & 0 & 91 & 93 & 94 & 99 & 93 & 93 & 98 & 92 \\
\hline N19 & VI & 98 & 87 & 89 & 0 & 88 & 90 & 69 & 65 & 79 & 0 & 0 & 91 & 94 & 96 & 100 & 94 & 95 & 98 & 92 \\
\hline N28 & VI & 95 & 87 & 97 & 0 & 88 & 87 & 97 & 88 & 93 & 98 & 0 & 91 & 95 & 97 & 100 & 92 & 0 & 95 & 90 \\
\hline N29 & VI & 97 & 88 & 0 & 0 & 88 & 89 & 91 & 87 & 84 & 94 & 0 & 93 & 96 & 95 & 100 & 93 & 92 & 97 & 91 \\
\hline N30 & VI & 98 & 89 & 98 & 0 & 88 & 88 & 90 & 87 & 88 & 96 & 0 & 91 & 94 & 96 & 100 & 93 & 93 & 98 & 92 \\
\hline N33 & VI & 95 & 87 & 98 & 0 & 94 & 88 & 91 & 89 & 89 & 93 & 0 & 91 & 93 & 97 & 100 & 93 & 93 & 95 & 91 \\
\hline N34 & VI & 95 & 87 & 95 & 0 & 93 & 88 & 98 & 87 & 93 & 99 & 0 & 91 & 95 & 95 & 98 & 94 & 93 & 95 & 91 \\
\hline N7 & VI & 98 & 89 & 97 & 0 & 88 & 88 & 92 & 87 & 84 & 94 & 0 & 91 & 93 & 94 & 99 & 93 & 93 & 98 & 92 \\
\hline N8 & VI & 91 & 88 & 98 & 0 & 88 & 85 & 91 & 87 & 84 & 92 & 0 & 91 & 92 & 95 & 99 & 94 & 0 & 91 & 89 \\
\hline N9 & VI & 98 & 87 & 98 & 0 & 87 & 89 & 90 & 89 & 88 & 96 & 0 & 91 & 93 & 96 & 99 & 93 & 92 & 98 & 92 \\
\hline
\end{tabular}


It appears from the table that when isolates 21 (the only group I isolate) and 16 (the only group III isolate) are not taken into account, the seventeen of the nineteen virulence genes are found in almost all the isolates, except for cytK2, which is restricted to six of the isolates from group IV (6 out of 10) and one from group V ( 1 of 8$)$, and for hlyII, which is present in two out of three of the isolates of group II and in eight out of ten of the isolates of group IV. Statistical analysis (Kruskal-Wallis test, $p<$ 0.05 , Table 5) reveals that, for all the translated genes, significant differences exist between the percent identity of at least two of the phylogenetic groups II, IV, V and VI. Group IV isolates have statistically significantly higher identity than group VI isolates for all genes except the sphingomyelinase (sph), while significant differences exist between group VI and groups II and V. For sph, significant differences exist between isolates of group II and the isolates from the other three groups. This association between the percent identity to the standard genes and the phylogenetic groups is further evidenced in a principal component analysis (PCA) performed to determine how the isolates cluster in a two-dimensional (2D) scatterplot according to phenotype combinations (Figure 2). We plotted the isolates according to their coordinates in the principal component 1 (F1) and 2 (F2). Using this coordinate system, four groups of isolates could be distinguished. It appears from the figure that F1 and F2 account for most of the initial variability in the data, with F1 describing the largest part $(60.83 \%)$. The squared cosines of the variables show that the percentage identity of all the genes, except sph, are linked to the first axis, while $s p h$ is linked to the second. The PCA separates the isolates into four groups, strongly relating to their phylogenetic groups. Isolates from groups IV, V and VI comprise three clusters, with the fourth cluster comprised of the three group II isolates along with the single group III isolate. The single group I isolate is clustered outside of these four groups. The four clusters are significantly different from each other (Kruskal-Wallis tests, $p>0.001$ ). It is also worth mentioning that genes for the production of the emetic toxin are not identified in any of the isolates. Genes for the biosynthesis of the anthrax capsule were restricted to isolate N31 (N.B. Hendriksen, Department of Environmental Science, Aarhus University, Denmark. The gene for the protein was detected in the WGS of isolate N31 by Btyper, 2020).

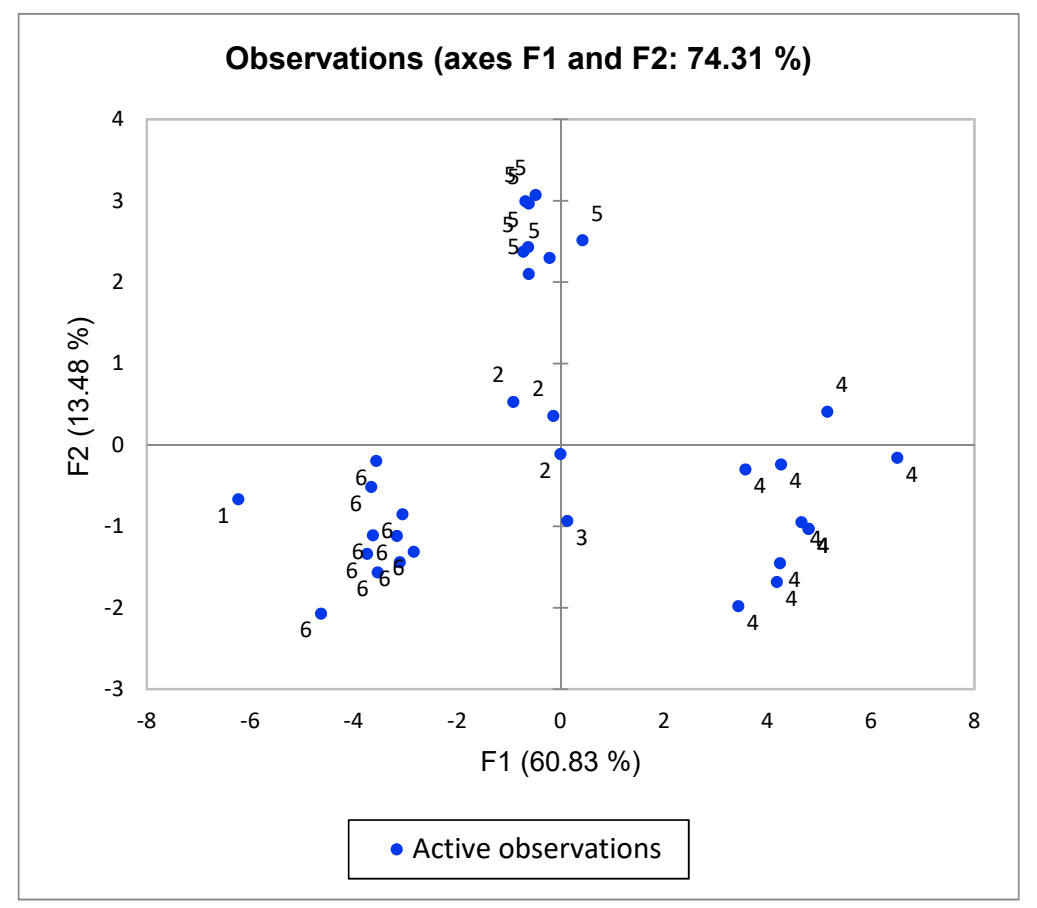

Figure 2. Principal component analysis (PCA) of presence and identity of 19 potential genes in $33 \mathrm{~B}$. cereuscereus sensu lato isolates with their affiliation to six phylogenetic groups shown. F1 relates to the percentage identity of all the genes, except sph, and F2 relates to the percentage identity of sph. Each isolate (blue spots) was plotted according to its values in PC analysis. 
Figure 3 shows the distribution of the 33 isolates divided into six phylogenetic groups in relation to the yearly mean temperature of the country where the soils were collected (https://www.weatherbase. com). The distribution is not random, as revealed by Chi-square analysis $(p<0.05)$. This seems to be caused by a higher number of isolates belonging to a phylogenetic group with a growth range above $10^{\circ} \mathrm{C}$ present in countries with mean temperatures above the median temperature of all the eleven countries, and then the opposite for the isolates belonging to phylogenetic groups having a growth starting below $10^{\circ} \mathrm{C}$, which are more prevalent in countries with median temperatures below or equal to the median temperature of all the eleven countries.

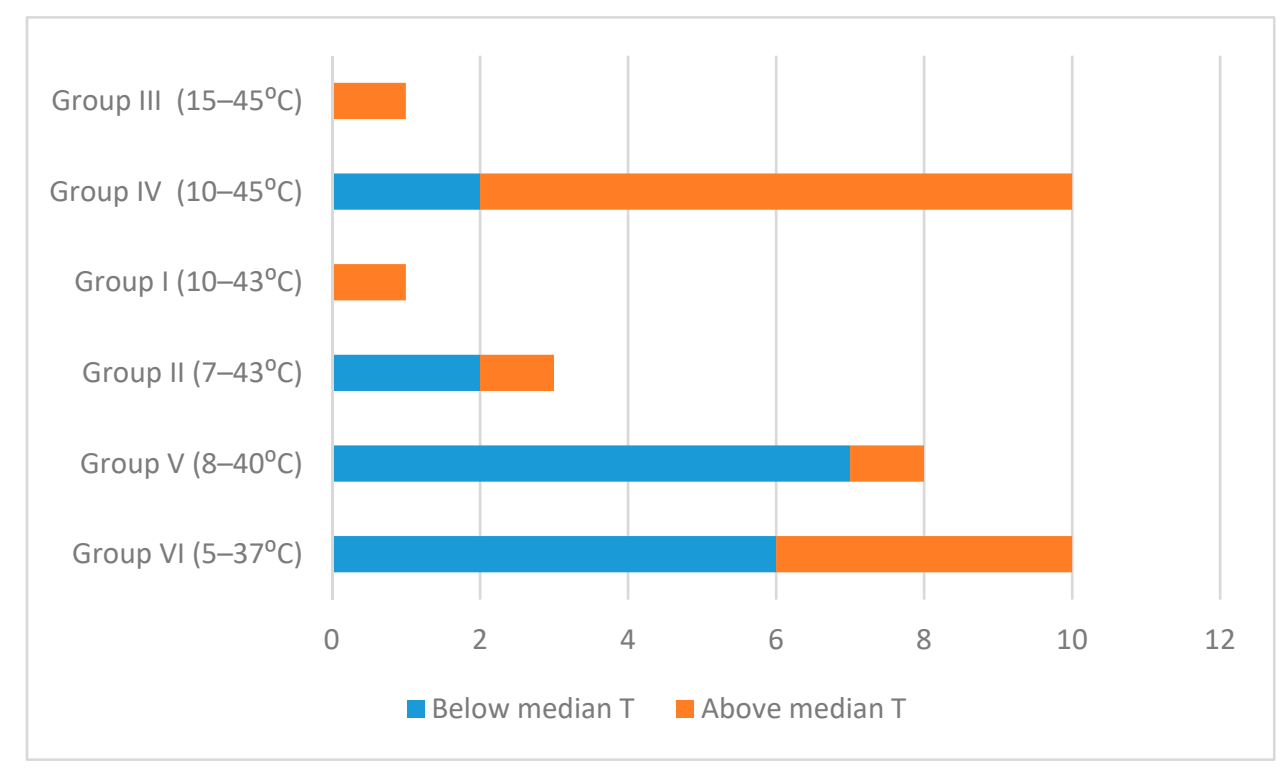

Figure 3. Numbers of $33 \mathrm{~B}$. cereus sensu lato isolates in five phylogenetic groups in relation to the annual mean temperature of soils from which they are isolated. Blue refers to numbers of isolates from soils with an annual mean temperature below or equal to the median annual temperature $\left(10.2{ }^{\circ} \mathrm{C}\right)$ of the 17 soils, and brown refers to numbers of isolates from soils with temperature above the median temperature. The temperature growth range of the six phylogenetic groups are shown [2].

\section{Discussion}

The genome of 33 B. cereus group isolates was whole genome sequenced using Illumina Nextseq. The assembled contigs of the 33 isolates shared comparable genome size and GC-content similar to values previously reported for B. cereus group strains [26] The same is the case with the number of tRNA and rRNA genes. The number of contigs varies between 173 and 4682, however the sequencing depth was sufficient to cover the breadth of the genomes. This fragmentation of the assemblies might be caused by the relatively low GC-content, the presence of several extra-chromosomal elements and highly abundant repeat elements $[27,28]$. In spite of this variation in fragmentation of the assemblies, the predicted number of proteins are similar among the isolates and comparable to numbers previously reported [26],

The considerable diversity among the 33 isolates, evidenced by the presence of 29 STs, including 11 new ones, most likely reflects that they are soil bacteria that occupy diverse ecological habitats that can survive as spores in soil reservoirs [14,29]. Some of the sequence types are determined with some uncertainty, because no allele in the current database matches with $100 \%$ identity to all seven of the analyzed alleles. The high correspondence between the division of the isolates into six phylogenetic groups by panC, MLST and ANI analyses is in accordance with the analysis done by Carroll et al. [15] and by Bazinet [6].

The isolates were identified at the species level with four different procedures and resulted in different outputs, as none of the isolates was identified as the same species with all four 
procedures. The number of species identified by the different procedures varies between 2 and 13. Traditional identification, based on several tests, divided the isolates into the species $B$. cereus and $B$. weihenstephanensis. Recently, it has been demonstrated that $B$. weihenstephanensis is a later synonym for B. mycoides [30].

Identification based on $16 \mathrm{~S}$ rRNA gene sequencing divided the isolates into six B. cereus group species, while three isolates were not identified to this group. The isolates identified as $B$. cereus, $B$. wiedmannii and $B$. toyonensis are members of more than one of the phylogenetic groups, while isolates belonging to $B$. mycoides, $B$. thuringiensis and B. pseudomycoides only belong to one group; however, $B$. thuringiensis and B. pseudomycoides are only represented by two or one isolate, respectively. Limitations in the use of $16 \mathrm{~S}$ rRNA gene sequencing for the phylogenetic-based classification of the B. cereus group have previously been shown [31]. The identification of species with Btyper3 is based on WGS and uses a threshold of $92.5 \%$ ANI for genomo-species clusters [7]. This methodology divides the isolates into the species B. mosaicus, B. cereus SS, B. toyonensis, B. mycoides and B. pseudomycoides, and further, four of the isolates belonging to B. cereus SS are Biovar thuringiensis. This identification reflects the division of the isolates into phylogenetic groups as four of the species correspond to a phylogenetic group, while B. mosaicus corresponds to the two neighboring groups II and III. The chosen threshold at 92.5\% ANI deviates from the widely accepted 95\% ANI threshold for current species definition [32], and it was chosen to create a strong relationship between identification to the species level and the known phylogenetic structure. If a threshold at 95\% ANI is chosen for analyzing the 33 isolates, one isolate each of the species B. mosaicus and B. mycoides must be considered as a new undescribed species according to Figure 1. Further, it must be noted that the Btyper3-based identification means that: (i) some isolates which by traditional methods would be identified as $B$. cereus are now considered as the new species $B$. mosaicus, (ii) isolates which do not have a rhizoid growth on agar plates are identified as B. mycoides or B. pseudomycoides and (iii) isolates possessing genes such as Cry75Aa3 and different vegetative insecticidal proteins are considered as Biovar thuringiensis, although they do not produce crystal proteins, a key identification characteristic for B. thuringiensis.

The TYGS-based identification is based on in silico DNA:DNA hybridization and species delimitation as described by Meier-Kolthoff et al. [5]. Based on the procedure, the 33 isolates are divided into the species B. cereus, B. wiedmanii, B. toyonensis, B. proteolyticus, B. mycoides, B. pseudomycoides and seven new species. This division of the isolates into species does not correspond to the phylogenetic division of the isolates into six groups. Indeed, although all isolates affiliated to phylogenetic group $\mathrm{V}$ are identified as B. toyonensis, two isolates also identified as B. toyonensis are affiliated to groups II and VI. The three new species comprising more than one isolate affiliated to the species are all restricted to one phylogenetic group, and this might reflect that the B. cereus group has a clonal phylogenetic structure [3]. The difference between the ANI-based and the TYGS-based identification reflects that the two methods interpret the phylogeny of the B. cereus group differently and use different definitions for the affiliation of isolates to species.

The identification performed by four different procedures points to the importance of describing how identification at the species level for the B. cereus group members has been executed.

Most of the 33 isolates across species and phylogenetic groups possessed seventeen of the nineteen analyzed genes for virulence factors, which corresponds to previous results $[7,29]$. It has also been found previously that $c y t K 2$ and hlyII are restricted to phylogenetic groups II, III and IV, and that those genes producing the emetic toxin and the B. anthracis capsule are notably restricted to a few clonal clusters in group III [7,15]. We reported a close association between percentage identity of the genes at the protein level to selected standard genes and the distribution of the isolates into six phylogenetic groups. Earlier reports have shown that cytotoxicity varies between the phylogenetic groups, and that nhe $A$ and $n h e B, h b l A$ and $h b l D$ and $c y t K$ genes are polymorphic $[8,33,34]$. It is unknown for most of these virulence factors whether different variants vary in virulence, except for $C y t K$, which exists in two forms, $C y t K 1$ and $C y t K 2$, that exhibit $89 \%$ sequence identity at the protein level. The two CytK proteins differ in their biological effects, as $C y t K-2$ forms pores with a lower conductance than those 
made by $C y t K-1$ [34-36], and compared to $C y t K-2, C y t K-1$ displays a higher toxicity towards human intestinal Caco-2 and Vero cells [35]. This indicates that the variability in the sequences of the different virulence factors can affect their biological effects. This question needs to be investigated further for the other polymorphic virulence factors present in the B. cereus group in the future.

Our data also show that distribution of the isolates is related to the mean temperatures of the countries, as the distribution is related to the phylogenetic groups, which in relation to temperature, relates to different ecotypes $[2,10,11]$. In other words, isolates of the most cold-adapted groups, II, V and VI, are more common in colder soils, while isolates of more mesophylic groups, I, III and IV, prevail in more temperate soils. The relationship between temperature and the geographical distribution of $B$. cereus has been investigated earlier and shown by von Stetten et al. [37].

In conclusion, the phylogeny, identification and characterization of $33 \mathrm{~B}$. cereus sensu lato isolates originating from 17 agricultural soils from 11 countries were analyzed on the basis of whole genome sequencing. Phylogenetic analyses divided the isolates into six groups that follow the phylogenetical division of $B$. cereus sensu lato proposed by several authors [1-3,6,7]. Identifications were based on four different methods with varied results, as none of the isolates were identified as the same species by all four methods: only the recent identification method proposed by Carroll et al. [7] directly reflected the phylogeny of the isolates. This points to the importance of describing the basis and method used for the identification. The presence and percent identity of the protein product of 19 genes potentially involved in pathogenicity divided the 33 isolates into four statistically different clusters, which corresponds to the generally accepted phylogenetic groups II, IV, V and VI. Phylogenetic groups I and III were each only presented by one isolate. This shows that different pathotypes exist and that it is possible to differentiate between them by comparing the percent identity of proteins potentially involved in pathogenicity. It also shows that a basic link between phylogeny and pathogenicity exists. Finally, the geographical distribution of the isolates was not random: they were distributed in relation to their division into the six phylogenetic groups, which again relates to different ecotypes with different temperature growth ranges $[2,10,11]$. This means that we find it easier to analyze and understand the results obtained about the $33 \mathrm{~B}$. cereus sensu lato isolates in a phylogenetic, patho-type and ecotype-oriented context, than in a context based on a method-dependent identification at the species level.

Author Contributions: A.Z., M.R.A., H.A., M.G., M.H., I.J., O.K., A.K., J.L., P.M., D.M., S..N., H.S., R.T., Z.T., F.Y., R.Z.Z., X.Z., V.S.-B. and N.B.H. were all involved in conceiving and designing the research, in the collection of soil samples, performing the laboratory work and the analysis of data. A.Z. did the sequencing and the basal bio-informatics. N.B.H. wrote the manuscript. A.Z. and N.B.H. created the figures. All authors have read and agreed to the published version of the manuscript.

Funding: The research was supported by the European Cooperation in Science and Technology's COST-action 16110 "Control of Human Pathogenic Microorganisms in Plant Production Systems (HUPLANTcontrol)" and is a result of the training school "Bacillus-identification, phylogeny and potential pathogenicity" hosted by the Department of Environmental Science, Aarhus University, Denmark, and planned by N.B.H. The supporters had no role in study design, data collection and analysis, decision to publish, or preparation of the manuscript.

Acknowledgments: We want to thank Klaus Condé Christensen, Tania Begovic and Tina Thane for technical assistance and other kinds of help during the training school. We are grateful to Jennifer Upfold for revising the English text.

Conflicts of Interest: The authors declare that the research was conducted in the absence of any commercial or financial relationships that could be interpreted as a potential conflict of interest.

\section{References}

1. Priest, F.G.; Barker, M.; Baillie, L.W.J.; Holmes, E.C.; Maiden, M.C.J. Population structure and evolution of the Bacillus cereus group. J. Bacteriol. 2004, 186, 7959-7970. [CrossRef] [PubMed]

2. Guinebretiere, M.H.; Thompson, F.L.; Sorokin, A.; Normand, P.; Dawyndt, P.; Ehling-Schulz, M.; De Vos, P. Ecological diversification in the Bacillus cereus Group. Environ. Microbiol. 2008, 10, 851-865. [CrossRef] [PubMed] 
3. Okinaka, R.T.; Keim, P. The Phylogeny of Bacillus cereus sensu lato. Microbiol. Spectr. 2016, 4. [CrossRef] [PubMed]

4. Liu, Y.; Lai, Q.L.; Goker, M.; Meier-Kolthoff, J.P.; Wang, M.; Sun, Y.M.; Shao, Z.Z. Genomic insights into the taxonomic status of the Bacillus cereus group. Sci. Rep. 2015, 5. [CrossRef] [PubMed]

5. Meier-Kolthoff, J.P.; Goker, M. TYGS is an automated high-throughput platform for state-of-the-art genome-based taxonomy. Nat. Commun. 2019, 10. [CrossRef]

6. Bazinet, A.L. Pan-genome and phylogeny of Bacillus cereus sensu lato. BMC Evol. Biol. 2017, 17. [CrossRef]

7. Carroll, L.M.; Wiedmann, M.; Kovac, J. Proposal of a Taxonomic Nomenclature for the Bacillus cereus Group Which Reconciles Genomic Definitions of Bacterial Species with Clinical and Industrial Phenotypes. Mbio 2020, 11. [CrossRef]

8. Fiedoruk, K.; Drewnowska, J.M.; Daniluk, T.; Leszczynska, K.; Iwaniuk, P.; Swiecicka, I. Ribosomal background of the Bacillus cereus group thermotypes. Sci. Rep. 2017, 7. [CrossRef]

9. Helgason, E.; Tourasse, N.J.; Meisal, R.; Caugant, D.A.; Kolsto, A.B. Multilocus sequence typing scheme for bacteria of the Bacillus cereus group. Appl. Environ. Microbiol. 2004, 70, 191-201. [CrossRef]

10. Drewnowska, J.M.; Swiecicka, I. Eco-Genetic Structure of Bacillus cereus sensu lato Populations from Different Environments in Northeastern Poland. PLoS ONE 2013, 8. [CrossRef]

11. Swiecicka, I.; Bartoszewicz, M.; Kasulyte-Creasey, D.; Drewnowska, J.M.; Murawska, E.; Yernazarova, A.; Mahillon, J. Diversity of thermal ecotypes and potential pathotypes of Bacillus thuringiensis soil isolates. FEMS. Microbiol. Ecol. 2013, 85, 262-272. [CrossRef] [PubMed]

12. Guinebretiere, M.H.; Velge, P.; Couvert, O.; Carlin, F.; Debuyser, M.L.; Nguyen-The, C. Ability of Bacillus cereus Group Strains To Cause Food Poisoning Varies According to Phylogenetic Affiliation (Groups I to VII) Rather than Species Affiliation. J. Clin. Microbiol. 2010, 48, 3388-3391. [CrossRef] [PubMed]

13. Bottone, E.J. Bacillus cereus, a Volatile Human Pathogen. Clin. Microbiol. Rev. 2010, 23, 382. [CrossRef] [PubMed]

14. Ehling-Schulz, M.; Lereclus, D.; Koehler, T.M. The Bacillus cereus Group: Bacillus Species with Pathogenic Potential. Microbiol. Spectr. 2019, 7. [CrossRef]

15. Carroll, L.M.; Kovac, J.; Miller, R.A.; Wiedmann, M. Rapid, High-Throughput Identification of Anthrax-Causing and Emetic Bacillus cereus Group Genome Assemblies via BTyper, a Computational Tool for Virulence-Based Classification of Bacillus cereus Group Isolates by Using Nucleotide Sequencing Data. Appl. Environ. Microbiol. 2017, 83. [CrossRef]

16. Travers, R.S.; Martin, P.A.W.; Reichelderfer, C.F. Selective Process for Efficient Isolation of Soil Bacillus spp. Appl. Environ. Microbiol. 1987, 53, 1263-1266. [CrossRef]

17. Hansen, B.M.; Leser, T.D.; Hendriksen, N.B. Polymerase chain reaction assay for the detection of Bacillus cereus group cells. Fems Microbiol. Lett. 2001, 202, 209-213. [CrossRef]

18. Willumsen, P.A.; Johansen, J.E.; Karlson, U.; Hansen, B.M. Isolation and taxonomic affiliation of N-heterocyclic aromatic hydrocarbon-transforming bacteria. Appl. Microbiol. Biotechnol. 2005, 67, 420-428. [CrossRef]

19. Chen, S.; Zhou, Y.; Chen, Y.; Gu, J. fastp: An ultra-fast all-in-one FASTQ preprocessor. Bioinformatics 2018, 34, 884-890. [CrossRef]

20. Seemann, T. Prokka: Rapid prokaryotic genome annotation. Bioinformatics 2014, 30, 2068-2069. [CrossRef]

21. Larsen, M.V.; Cosentino, S.; Rasmussen, S.; Friis, C.; Hasman, H.; Marvig, R.L.; Lund, O. Multilocus Sequence Typing of Total-Genome-Sequenced Bacteria. J. Clin. Microbiol. 2012, 50, 1355-1361. [CrossRef] [PubMed]

22. Lechner, S.; Mayr, R.; Francis, K.P.; Pruss, B.M.; Kaplan, T.; Wiessner-Gunkel, E.; Scherer, S. Bacillus weihenstephanensis sp. nov. is a new psychrotolerant species of the Bacillus cereus group. Int. J. Syst. Bacteriol. 1998, 48, 1373-1382. [CrossRef] [PubMed]

23. Katoh, K.; Misawa, K.; Kuma, K.; Miyata, T. MAFFT: A novel method for rapid multiple sequence alignment based on fast Fourier transform. Nucleic Acids Res. 2002, 30, 3059-3066. [CrossRef] [PubMed]

24. Stamatakis, A. RAxML version 8: A tool for phylogenetic analysis and post-analysis of large phylogenies. Bioinformatics 2014, 30, 1312-1313. [CrossRef] [PubMed]

25. Hansen, B.M.; Hoiby, P.E.; Jensen, G.B.; Hendriksen, N.B. The Bacillus cereus bceT enterotoxin sequence reappraised. FEMS Microbiol. Lett. 2003, 223, 21-24. [CrossRef]

26. NCBI. Available online: https://www.ncbi.nlm.nih.gov/genome/browse\#!/prokaryotes/bacillus\%20cereus (accessed on 5 November 2020). 
27. Klassen, J.L.; Currie, C.R. Gene fragmentation in bacterial draft genomes: Extent, consequences and mitigation. BMC Genom. 2012, 13. [CrossRef] [PubMed]

28. Cahill, M.J.; Koser, C.U.; Ross, N.E.; Archer, J.A.C. Read Length and Repeat Resolution: Exploring Prokaryote Genomes Using Next-Generation Sequencing Technologies. PLoS ONE 2010, 5. [CrossRef]

29. Ceuppens, S.; Boon, N.; Uyttendaele, M. Diversity of Bacillus cereus group strains is reflected in their broad range of pathogenicity and diverse ecological lifestyles. FEMS Microbiol. Ecol. 2013, 84, 433-450. [CrossRef]

30. Liu, Y.; Lai, Q.L.; Shao, Z.Z. Genome analysis-based reclassification of Bacillus weihenstephanensis as a later heterotypic synonym of Bacillus mycoides. Int. J. Syst. Evol. Microbiol. 2018, 68, 106-112. [CrossRef]

31. Bavykin, S.G.; Lysov, Y.P.; Zakhariev, V.; Kelly, J.J.; Jackman, J.; Stahl, D.A.; Cherni, A. Use of 16S rRNA, $23 S$ rRNA, and gyrB gene sequence analysis to determine phylogenetic relationships of Bacillus cereus group microorganisms (vol 42, pg 3711, 2004). J. Clin. Microbiol. 2006, 44, 2676. [CrossRef]

32. Jain, C.; Rodriguez-R, L.M.; Phillippy, A.M.; Konstantinidis, K.T.; Aluru, S. High throughput ANI analysis of 90K prokaryotic genomes reveals clear species boundaries. Nat. Commun. 2018, 9. [CrossRef] [PubMed]

33. Beecher, D.J.; Wong, A.C.L. Tripartite haemolysin BL: Isolation and characterization of two distinct homologous sets of components from a single Bacillus cereus isolate. Microbiology-Sgm 2000, 146, 1371-1380. [CrossRef] [PubMed]

34. Fagerlund, A.; Ween, A.; Lund, T.; Hardy, S.P.; Granum, P.E. Genetic and functional analysis of the cytK family of genes in Bacillus cereus. Microbiology-Sgm 2004, 150, 2689-2697. [CrossRef] [PubMed]

35. Hardy, S.P.; Lund, T.; Granum, P.E. CytK toxin of Bacillus cereus forms pores in planar lipid bilayers and is cytotoxic to intestinal epithelia. FEMS Microbiol. Lett. 2001, 197, 47-51. [CrossRef]

36. Lund, T.; De Buyser, M.L.; Granum, P.E. A new cytotoxin from Bacillus cereus that may cause necrotic enteritis. Mol. Microbiol. 2000, 38, 254-261. [CrossRef]

37. von Stetten, F.; Mayr, R.; Scherer, S. Climatic influence on mesophilic Bacillus cereus and psychrotolerant Bacillus weihenstephanensis populations in tropical, temperate and alpine soil. Environ. Microbiol. 1999, 1, 503-515. [CrossRef]

Publisher's Note: MDPI stays neutral with regard to jurisdictional claims in published maps and institutional affiliations.

(C) 2020 by the authors. Licensee MDPI, Basel, Switzerland. This article is an open access article distributed under the terms and conditions of the Creative Commons Attribution (CC BY) license (http://creativecommons.org/licenses/by/4.0/). 